OPEN ACCESS

Edited by:

Roland Michael Tisch, University of North Carolina at Chapel

Hill, United States

Reviewed by:

Carolin Daniel,

Helmholtz-Gemeinschaft Deutscher

Forschungszentren (HZ), Germany

Jon D. Piganelli,

University of Pittsburgh, United States

*Correspondence:

Todd M. Brusko

tbrusko@ufl.edu

orcid.org/0000-0003-2878-9296

${ }^{\dagger}$ These authors have contributed equally to this work and share first authorship

Specialty section:

This article was submitted to Immunological Tolerance and Regulation,

a section of the journal

Frontiers in Immunology

Received: 09 July 2021 Accepted: 31 August 2021 Published: 16 September 2021

Citation:

Sharp RC, Brown ME, Shapiro MR, Posgai AL and Brusko TM (2021) The Immunoregulatory Role of the Signal Regulatory Protein Family and CD47 Signaling Pathway in Type 1 Diabetes.

Front. Immunol. 12:739048.

doi: 10.3389/fimmu.2021.739048

\section{The Immunoregulatory Role of the Signal Regulatory Protein Family and CD47 Signaling Pathway in Type 1 Diabetes}

\author{
Robert C. Sharp ${ }^{1 \dagger}$, Matthew E. Brown ${ }^{1 \dagger}$, Melanie R. Shapiro ${ }^{1}$, Amanda L. Posgai ${ }^{1}$ \\ and Todd M. Brusko ${ }^{1,2 *}$
}

1 Department of Pathology, Immunology, and Laboratory Medicine, College of Medicine, University of Florida, Gainesville, FL, United States, ${ }^{2}$ Department of Pediatrics, College of Medicine, Diabetes Institute, University of Florida, Gainesville, FL, United States

Background: The pathogenesis of type 1 diabetes (T1D) involves complex genetic susceptibility that impacts pathways regulating host immunity and the target of autoimmune attack, insulin-producing pancreatic $\beta$-cells. Interactions between risk variants and environmental factors result in significant heterogeneity in clinical presentation among those who develop T1D. Although genetic risk is dominated by the human leukocyte antigen (HLA) class II and insulin (INS) gene loci, nearly 150 additional risk variants are significantly associated with the disease, including polymorphisms in immune checkpoint molecules, such as SIRPG.

Scope of Review: In this review, we summarize the literature related to the T1Dassociated risk variants in SIRPG, which include a protein-coding variant (rs6043409, $\mathrm{G}>\mathrm{A} ; \mathrm{A} 263 \mathrm{~V}$ ) and an intronic polymorphism (rs2281808, C>T), and their potential impacts on the immunoregulatory signal regulatory protein (SIRP) family:CD47 signaling axis. We discuss how dysregulated expression or function of SIRPs and CD47 in antigenpresenting cells (APCs), T cells, natural killer (NK) cells, and pancreatic $\beta$-cells could potentially promote T1D development.

Major Conclusions: We propose a hypothesis, supported by emerging genetic and functional immune studies, which states a loss of proper SIRP:CD47 signaling may result in increased lymphocyte activation and cytotoxicity and enhanced $\beta$-cell destruction. Thus, we present several novel therapeutic strategies for modulation of SIRPs and CD47 to intervene in T1D.

Keywords: CD47, SIRPG, SIRPA, SIRPB1, type 1 diabetes, signal regulatory protein

\section{INTRODUCTION}

Type 1 diabetes (T1D) pathogenesis involves marked failures in immunoregulation and an adaptive immune response targeting $\beta$-cell autoantigens expressed in the pancreatic islets of Langerhans. Genome-wide association studies (GWAS) have shown that T1D is a highly polygenic disease (1-3). The majority of T1D risk is conferred by the highly polymorphic human leukocyte antigen (HLA) 
class II region and the insulin locus; however, there are nearly 150 additional single nucleotide polymorphisms (SNPs) associated with T1D risk $(1,3,4)$. A subset of these SNPs impact $\mathrm{CD}^{+}$and $\mathrm{CD}^{+} \mathrm{T}$ cell function, including risk variants tagged to co-stimulatory and co-inhibitory molecules CD226, CTLA4, and SIRPG $(2,3)$.

Among these variants, those associated with SIRPG (signal regulatory protein gamma), which encodes the receptor-like transmembrane protein SIRP $\gamma$, have been proposed to modulate $\mathrm{T}$ cell and natural killer (NK) cell activation (5-7). SIRPG contains two SNPs associated with risk for T1D $(5,8-12)$ : rs2281808 [C>T, intronic, minor allele frequency (MAF): 0.27, odds ratio (OR): 1.11] and rs6043409 (G>A, Ala263Val, MAF: 0.20 , OR 1.13). These SNPs are in tight linkage disequilibrium (LD) $\left(R^{2}=0.94 ; D^{\prime}=0.98\right)(8,10,13-15)$ and tend to be inherited as a haplotype that carries either risk $(\mathrm{C} / \mathrm{G}, 65.2 \%)$ or protection (T/A, 33.5\%) from T1D in European cohorts (13). In addition to T1D, rs2281808 and rs6043409 are associated with other T cellmediated autoimmune diseases, such as rheumatoid arthritis (RA), systemic lupus erythematosus (SLE), and ulcerative colitis (UC) $(6-8,10,14-17)$.

While much of the impact of SIRPG risk variants have yet to be empirically determined, bioinformatic analysis of the locus provides some insight into how variants may impact expression and processing. SIRPG is predicted to exhibit three different isoforms with isoform 1 being the most predominant and encoding the longest form of the protein. Alternative splicing results in the production of shorter isoforms 2 and 3 (modeled in Figure 1A) $(6,18,19)$ which lack a majority of the transmembrane domain and thus, might allow for secretion of the SIRP $\gamma$ protein rather than expression on the cell surface. The intronic T1D risk allele $(\mathrm{C}$; rs2281808) may be associated with a decreased SIRPG intronexcision ratio in whole blood and spleen [Data Source: GTEx Analysis Release V8 (dbGaP Accession phs000424.v8.p2)] (20). Hence, we speculate that the risk allele could potentially increase the predominance of isoforms 2 and 3 due to interrupted splicing of the

\footnotetext{
Abbreviations: T1D, Type 1 Diabetes; HLA, Human Leukocyte Antigen; INS, Insulin; SIRP, Signal Regulatory Protein; APCs, Antigen-Presenting Cells; SNPs, Single Nucleotide Polymorphisms; NK, Natural Killer; MAF, Minor Allele Frequency; OR, Odds Ratio; LD, Linkage Disequilibrium; RA, Rheumatoid Arthritis; SLE, Systemic Lupus Erythematosus; UC, Ulcerative Colitis; IAP, Integrin-Associated Protein; eQTL, Expression Quantitative Trait Loci; Ig, Immunoglobulin; ITIMs, Immunoreceptor Tyrosine-based Inhibition Motifs; SHP 1/2, SH2-domain-containing Protein Phosphatase 1/2; DC, Dendritic Cells; DAP12, DNAX-Activation Protein 12; ITAMs, Immunoreceptor Tyrosine-based Activation Motifs; VEGFR-2, Vascular Endothelial Growth Factor Receptor-2; TSP-1, Thrombospondin-1; Gi, Inhibitory G Protein; BNIP3, BCL2 Interacting Protein 3; RBCs, Red Blood Cells; NOD, Non-Obese Diabetic; HUVEC, Human Umbilical Vein Endothelial Cell; PD-1, Program Cell Death Protein 1; CTLA-4, Cytotoxic T-Lymphocyte-Associated Protein 4; IFN- $\gamma$, Interferon Gamma; Th, T helper; HEL, Hen Egg Lysozyme; MHEC, Murine Heart Endothelial Cell; NOR, Nonobese T1D-resistant; FOXP3 ${ }^{+}$, Forkhead box P3; TCR, T Cell Receptor; DN, Double Negative; ZAP70, Zeta-chain-Associated Protein; ERK, Extracellular signal-Regulated Kinases; MAPK, Mitogen-Associated Protein Kinase; $\mathrm{H}_{2} \mathrm{~S}$, Hydrogen Sulfide; EGR-1, Early Growth Response gene-1; PTPN2, Protein Tyrosine Phosphatase Non-receptor 2; TNFAIP3, Tumor Necrosis Factor, Alpha-Induced Protein 3; $\mathrm{Ca}^{2+}$, Calcium; AP-1, Activator Protein 1; UPR, Unfolded Protein Response; IGF-1, Insulin-Like Growth Factor-1; TEDDY, The Environmental Determinants of Diabetes in the Young.
}

full-length isoform lowering overall SIRP $\gamma$ expression on the cell surface (Figures 1C, D) $(18,19)$.

The exonic risk allele (G; rs6043409; alanine (Ala;A) codon) alters the structure of the extracellular D3 domain of SIRP $\gamma$, the function of which is currently unknown (Figure 1B) (15). It is possible that the conformation of the D1 and D2 domains of SIRP $\gamma$, which facilitate binding to the integrin-associated protein (IAP; CD47), could be impaired by the Ala mutation in the nearby D3 domain, inhibiting this protein-protein interaction (Figures 1C, D) (15). In turn, the protective allele [A; valine (Val; $\mathrm{V})$ codon] could alter the D3 domain of SIRP $\gamma$ and thereby enhance CD47 binding, but this has not been confirmed at this time (15). Further experiments are warranted to validate the predicted impacts of these risk variants on altered splicing and expression of SIRPG, along with their downstream effects on immune cell activation and function.

Although SIRP $\gamma$ is the only member of the SIRP family with known T1D risk loci, other proteins found in this family, such as SIRP $\alpha$ and SIRP $\beta 1$, may also be involved in T1D pathogenesis. For example, the rs2281808 and rs6043409 risk variants are expression quantitative trait loci (eQTL) for both SIRPG and SIRPB1, whereby SIRP $\gamma$ expression is reduced and SIRP $\beta 1$ expression is reciprocally increased (21). Thus, it is of importance to examine not only SIRP $\gamma$ but also, other members of the SIRP family and their binding partner CD47 as a potential pathway of interest in T1D.

CD47 is ubiquitously expressed and is well known for providing a "don't eat me" signal via binding to SIRP $\alpha$ on macrophages, which prevents macrophage-mediated phagocytosis and destruction of CD47-expressing target cells $(22,23)$. CD47 is also involved in the regulation of apoptosis, proliferation, adhesion, and migration of immune cells (24-28) as well as metabolic signaling in $\beta$-cells $(29,30)$. However, there remains limited understanding of the functional impact of SIRPG risk variants on SIRP:CD47 signaling and downstream immune cell activation and proliferation, as well as on pancreatic $\beta$-cell survival and function in the context of T1D pathogenesis. We hypothesize that the T1Drisk alleles of rs2281808 and rs604309 tagged to SIRPG might result in reduced CD47 binding capability or decreased expression of SIRP $\gamma$ on T cells and NK cells (Figure 2). We pose that the SIRP: CD47 signaling pathway could be an important element in the regulation of autoimmunity. In this review, we describe the SIRP: CD47 signaling pathway and highlight potential functional implications of the T1D-associated SIRPG SNPs. We also discuss various strategies for modulating SIRPs/CD47 signaling to intervene in T1D.

\section{STRUCTURAL FEATURES AND SIGNALING PATHWAYS OF SIRPS:CD47}

\section{SIRP Family}

SIRP $\alpha$, SIRP $\beta 1$, and SIRP $\gamma$, which comprise the SIRP family, are type 1 transmembrane glycoproteins with three immunoglobulin-like (Ig-like) extracellular regions, a single transmembrane domain, and varying cytoplasmic domains 
A

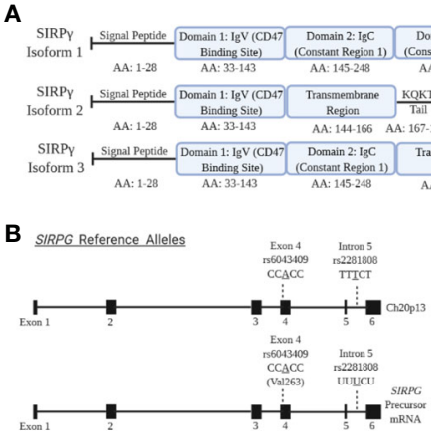

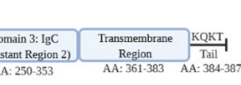

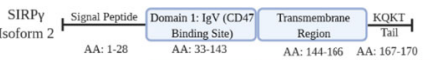

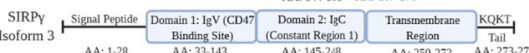

B

Protective Alleles
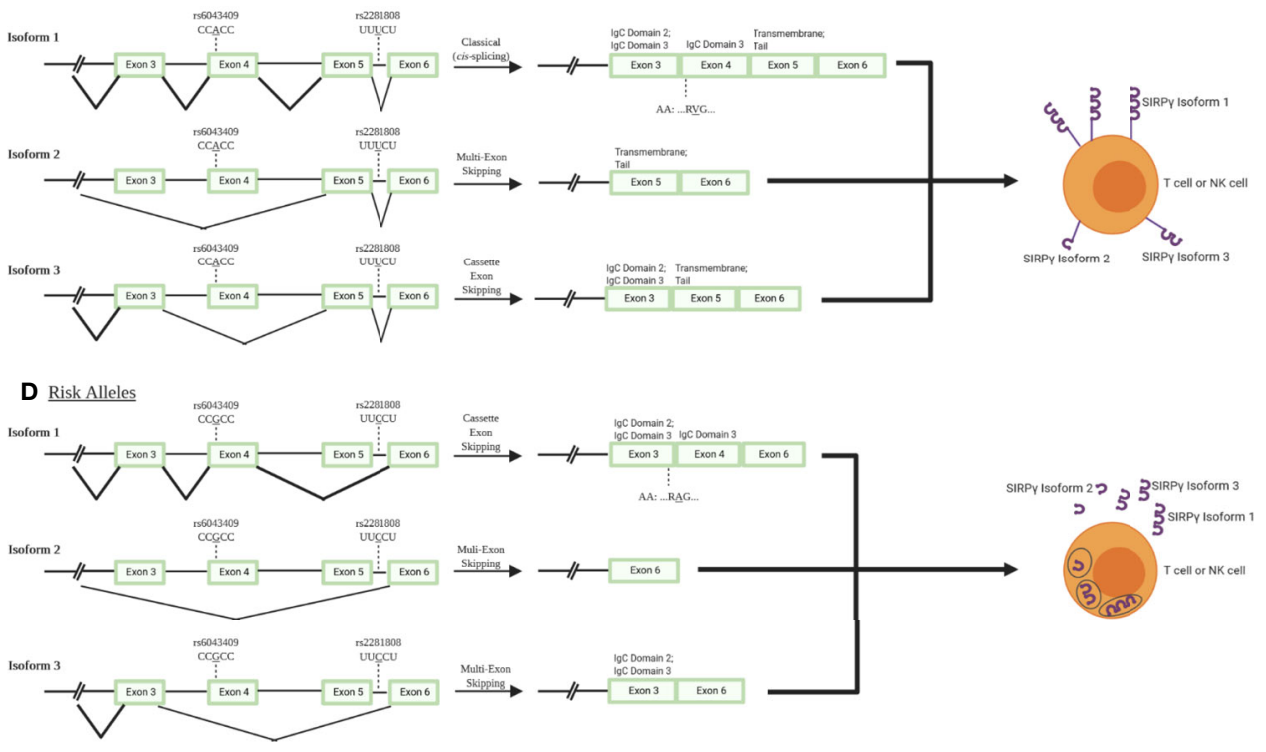

FIGURE 1 | SIRP $\gamma$ isoforms and predicted consequences of rs2281808 and rs6043409 SNPs: T1D-associated SNPs in signal regulatory protein gamma (SIRPG) may alter splicing activity and thereby surface SIRPG expression. (A) Isoform 1 (NCBI Reference Sequence: NP_061026.2) is the longest and most predominant form of the protein, while isoform 2 (NP_543006.2) and isoform 3 (NP_001034597.1) are shorter and less frequently observed (18, 19). All isoforms contain domain 1 (D1), which is the immunoglobulin variable (lgV) region that binds to CD47. However, only isoform 1 contains two immunoglobulin constant (lgC) regions and a known transmembrane region at the end of the protein structure. Isoform 3 contains at least one IgC, while isoform 2 has no constant region. (B) Gene and pre-mRNA diagrams of SIRPG (NCBI reference sequence for gene: NC_000020.11, Gene ID: 55423; precursor mRNA for isoform 1: NM_018556.41). Reference and alternative alleles for rs2281808 and rs6043409 are shown. (C) We speculate that the protective alleles of rs2281808 and rs6043409 are associated with "normal" SIRPG splicing and high membrane SIRP $\gamma$ expression on T cells and NK cells, while (D) SIRPG risk alleles might promote aberrant splicing, potentially resulting in a loss of exon 5 , which encodes most of the transmembrane region. We expect this would cause lower membrane expression of SIRP $\gamma$ as well as increased SIRP $\gamma$ secretion.

(Figure 2) (5, 31). The cytoplasmic tail of SIRP $\alpha$ contains two immunoreceptor tyrosine-based inhibitory motifs (ITIMs), which interact with Src homology region 2-domain-containing phosphatase 1 (SHP1) and $\operatorname{SHP} 2(5,31,32)$. In antigenpresenting cells (APCs), such as dendritic cells (DCs) and macrophages/monocytes, SIRP $\alpha$-induced SHP1/2 activation downregulates pro-inflammatory processes including cytokine/ chemokine production, cellular adhesion, and phagocytosis (Figure 2A) (5, 31, 32). In contrast, SIRP $\beta 1$ and SIRP $\gamma$ do not contain signaling motifs in their cytoplasmic domains. SIRP $\beta 1$ has a small six-amino acid tail that interacts with DNAXactivation protein 12 (DAP12), a transmembrane adaptor protein that contains immunoreceptor tyrosine-based activation motifs (ITAMs) $(5,31) . \operatorname{SIRP} \gamma$, which has no ortholog in murine or other animal models, has a four-amino acid cytoplasmic tail that has not been shown to interact with adaptor proteins; thus, SIRP $\gamma$ is hypothesized to function as a "decoy receptor" that competes for CD47 binding with SIRP $\alpha$ (5, 31). CD47 is a transmembrane protein in the Ig superfamily, with a single IgV-like domain at its extracellular N-terminus that binds to several integrins, vascular endothelial growth factor receptor-2 (VEGFR-2), CD36, Fas/CD95, thrombospondin-1 (TSP-1), SIRP $\alpha$, and $\operatorname{SIRP} \gamma(23,34)$. CD47 contains five membrane-spanning segments and a C-terminus cytoplasmic domain. Upon ligand binding to CD47, a heterotrimeric inhibitory $\mathrm{G}$ protein $(\mathrm{Gi})$ is recruited to its cytoplasmic tail $(25,33)$, controlling various immunoregulatory processes, such as activation and apoptosis (through BCL2 interacting protein 3 


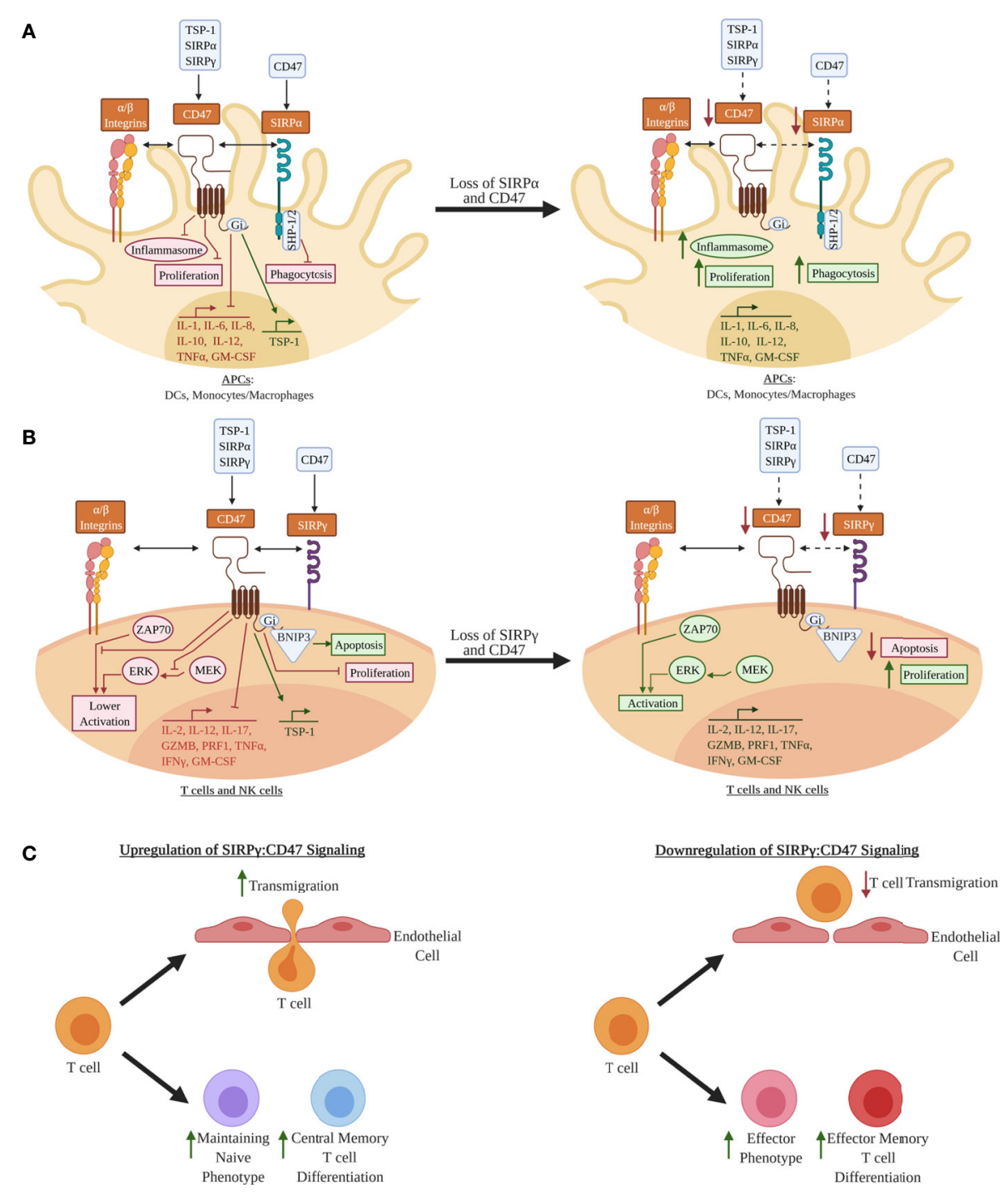

FIGURE 2 | Hypothetical model for how decreased SIRPs CD47 signaling may lead to a pro-inflammatory phenotype in leukocytes: (A) In antigen-presenting cells (APCs) such as dendritic cells (DCs) and monocytes/macrophages, signal regulatory protein alpha (SIRP $\alpha$ ) and CD47 are co-expressed, whereby SIRP $\alpha$ can bind CD47 expressed on other cell types (e.g., leukocytes, epithelial cells, endothelial cells) in trans or possibly via in cis interactions, thus activating the immunoreceptor tyrosine-based inhibitory motifs (ITIMs) on its cytoplasmic tail $(5,22,23,31,32)$. CD47 is activated by either thrombospondin 1 (TSP-1), SIRP $\alpha$, or SIRP $\gamma$, where it is hypothesized that inhibitory $\mathrm{G}$ protein (Gi) binding inhibits inflammasome activation, pro-inflammatory cytokine expression, proliferation, and phagocytosis (25, 33). These processes may be augmented if SIRP $\alpha$ and/or CD47 expression are decreased. (B) SIRP $\gamma$ and CD47 are co-expressed in T and natural killer (NK) cells (5-7, 31). CD47 ligation is hypothesized to inhibit T and NK cell activation via inhibition of unknown downstream elements of the zeta chain of T cell receptor-associated protein kinase 70 (ZAP70) activation, inhibition phosphorylation of the mitogen-associated protein kinase (MEK), and inhibition of phosphorylation of the extracellular signal-regulated kinases (ERK) (26, 34-37). BCL2 interacting protein 3 (BNIP3) is a mediator of apoptosis that may be upregulated by activation of CD47 (24, 34, 38). Decrease expression of CD47 and/or SIRP $\gamma$ could potentially augment T cells and NK cells in a way that results in a more activated phenotype and increase proliferation in these immune cells. (C) Other examples of the effect of SIRP $\gamma$ :CD47 signaling in T cells. Upregulation of CD47 signaling is hypothesized to increase T cell transmigration; however, it is not known for sure if this increase in transmigration alters activation of the T cell $(39,40)$. CD47 ligation is also hypothesized to help maintain the naivety of T cells, and, once activated, promotes these T cells to differentiate to a more central memory phenotype (41-43). If loss of SIRP $\gamma$ :CD47 signaling occurs in T cells, it is hypothesized that this will contribute towards the differentiation to more effector and effector memory phenotypes along with a loss of transmigration. Red Text/Box: Inhibition; Green Text/Box: Activation.

(BNIP3) translocation) in DCs, monocytes/macrophages, T cells, and NK cells (Figure 2A, B) (24).

$\operatorname{SIRP} \alpha$ is expressed on a wide variety of cell types including many leukocyte subsets (e.g., monocytes, macrophages, DCs, NK cells), epithelial/endothelial cells, and other complex tissues (e.g., brain, pancreas) $(31,32,44)$, while SIRP $\gamma$ shows more restricted expression (Figure 2A, B) $(5,31)$. Specifically, SIRP $\gamma$ is found on $\mathrm{CD}^{+}$and $\mathrm{CD}^{+}{ }^{+} \mathrm{T}$ cells along with NK cells, where its function remains contested as promoting either activation or inhibition of these subsets $(5,31)$. SIRP $\beta 1$ is expressed on monocytes/ 
macrophages and DCs, however, its ligand remains unknown as it does not bind to $\operatorname{CD} 47(5,31,32)$. Hence, this review will examine the SIRP:CD47 family signaling axis and its potential role in T1D pathogenesis, centering on the impacts of SIRP $\alpha$, SIRP $\gamma$, and CD47 on immune cell function, along with that of SIRP $\alpha$ and CD47 on $\beta$-cell survival and insulin production (Figure 3).

\section{Implications of SIRPo:CD47 Signaling in APCs in T1D}

The systematic failure to regulate self-antigen reactivity along with a pro-inflammatory cytokine signature has been shown to contribute to $\mathrm{T}$ cell-mediated destruction of $\beta$-cells in T1D $(46,47)$. Additionally, the involvement of APCs, such as monocytes/macrophages, in $\beta$-cell destruction has been hypothesized to further promote T1D pathogenesis (46-48). During pancreatic organogenesis, macrophage precursors are present in developing islets where they promote $\beta$-cell proliferation and survival (49-52). After islet maturation, $\beta$-cell mass increases during the postnatal period over the first two to three years of life, with tissue-resident macrophages playing a supporting role in growth and development (49-52). Throughout the pancreas, a tightly regulated balance of M1 (classically activated, pro-inflammatory) and M2 (alternatively activated, immunoregulatory) macrophage polarization occurs (49-52). M1 macrophages are required for protection from microbial infection and overall injury, whereas M2 macrophages are required to induce $\beta$-cell proliferation, cytotoxic protection, and prevent inflammatory responses (49-53). Throughout T1D pathogenesis, a significant increase in pancreatic tissue-resident M1 macrophages and a compensatory decrease in M2 macrophages occurs, increasing localized inflammation and promoting infiltration of more macrophages into the pancreas $(46,48,54)$. As such, reduction
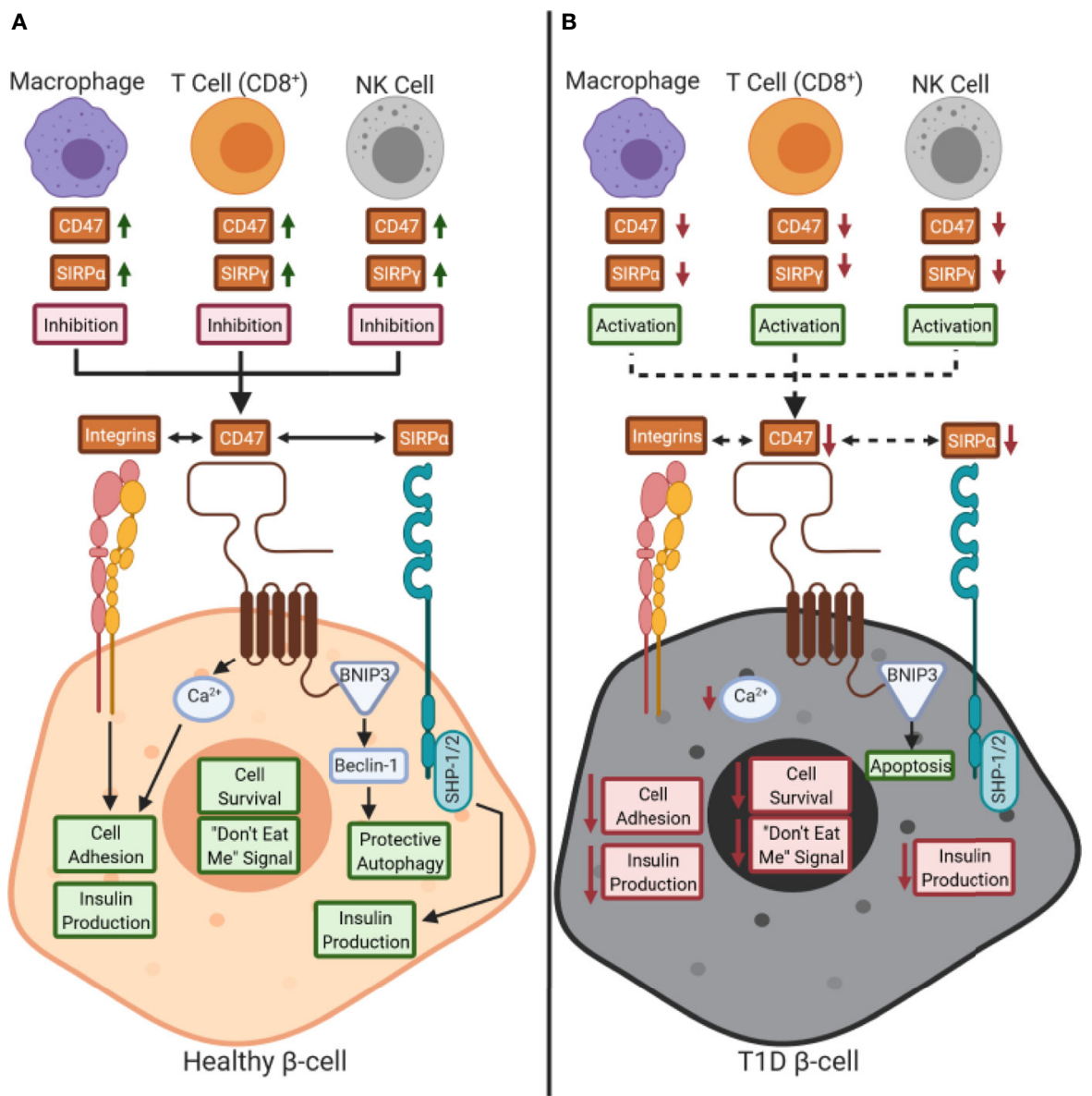

FIGURE 3 | Working model of the role of CD47:SIRPs signaling in health and during type 1 diabetes pathogenesis: (A) CD47 and signal regulatory protein (SIRP) are expressed by immune cells during a healthy state. CD47 controls calcium $\left(\mathrm{Ca}^{2+}\right)$ signaling in $\beta$-cells, through an unknown pathway, that promotes both cell adhesion and insulin production as well $(29,30,34,45)$. Also, CD47 is hypothesized to control protective autophagy via BCL2 interacting protein 3 (BNIP3) and Beclin-1 binding $(34,38)$. CD47 and SIRP $\alpha$ signaling can occur either in trans or in cis with each other or with other ligands, such as SIRP $\gamma$. We hypothesize that a reduction of SIRP expression and/or activity occurs on immune cells in type 1 diabetes (T1D), thus inhibiting peripheral immune tolerance. (B) Decreased CD47 and SIRP $\alpha$ activity in $\beta$-cells could potentially inhibit insulin secretion and cell survival while increasing immune cell-mediated destruction. Red text box: inhibition; green text box: activation; dashed arrows: inhibition. 
of SIRP $\alpha$ and/or CD47 expression has been suggested to increase APC activation, proliferation, and phagocytic capacity (Figure 2A), characteristic of pro-inflammatory T1Dassociated M1 macrophage polarization (31, 46-48, 54-56).

Once an immune response has been resolved and APC activation is no longer required, CD47 expression is upregulated to inhibit inflammasome activation (57-59) and the production of pro-inflammatory cytokines, including IL-12, TNF- $\alpha$, IL-6, and GM-CSF $(57,58,60)$. Inhibition of this proinflammatory milieu may contribute toward the mechanisms by which SIRP $\alpha$ modulates macrophage polarization. Accordingly, C57BL/6 mice with SIRP $\alpha$ overexpression exhibited an antiinflammatory M2 macrophage phenotype while SIRP $\alpha$ knockdown promoted a predominantly pro-inflammatory M1 macrophage phenotype (61). M2 macrophages express higher levels of SIRP $\alpha$ than M1 macrophages, and M2 macrophagesecreted IL-8 has been shown to increase CD47 expression on disseminated colon cancer cells, thereby preventing their phagocytosis (62). Tseng and colleagues further demonstrated that treatment of the DLD1 human colon cancer cell line with anti-CD47 blocking antibody (clone B6H12) facilitated their phagocytosis by macrophages, which subsequently increased their ability to prime $\mathrm{CD}^{+} \mathrm{T}$ cells for proliferation and cytotoxicity as compared to macrophages cultured with DLD1 cells in the absence of anti-CD47 (63). Critically, a non-blocking anti-CD47 antibody (clone 2D3) did not impart comparable effects (63). Under the same conditions, B6H12 mediated phagocytosis of cancer cells reduced the ability of macrophages to stimulate $\mathrm{CD}^{+} \mathrm{T}$ cell proliferation but also, significantly reduced the percentage of $\mathrm{CD} 4^{+} \mathrm{FOXP}^{+}$regulatory $\mathrm{T}$ cells in co-culture (63).

Similarly, during viral infections, CD47 expression increases on both immune cells and infected tissues due to an indirect effect of TNF $\alpha$-NFKB1-signaling (64). It is hypothesized that this effect occurs to prevent the over-activation of immune cells during infection, but it remains unknown whether viruses or bacteria can directly influence CD47 expression to evade detection by the immune system (64). Regardless, once downregulation or blockade of SIRP $\alpha$ :CD47 signaling occurs, most immune cells exhibit enhanced anti-viral capabilities (64). In line with these findings, adoptively transferred CD47-deficient red blood cells (RBCs) are cleared more quickly than $\mathrm{CD} 47^{+}$ $\mathrm{RBCs}$ in non-autoimmune $\mathrm{C} 57 \mathrm{BL} / 6$ recipient mice, supporting the notion that CD47 expression is required for successful "don't eat me" signaling (65). Interestingly, proinflammatory conditions or backcross to the autoimmune-prone non-obese diabetic (NOD) background (65) further accelerate the clearance of CD47-deficient RBCs (66). Altogether, these data suggest that SIRPo:CD47 signaling is particularly important for regulating immune responses in the context of cancer, infectious challenge and potentially, $\beta$-cell stress in subjects with high genetic risk for autoimmunity and specifically, T1D. Furthermore, these data suggest that interruptions or deficiencies in SIRP $\alpha: C D 47$ could promote the engulfment, processing, and aberrant presentation of self-antigens to T cells during the pathogenesis of T1D. Studies of SIRP $\alpha$ and/or CD47 expression on both DCs and monocytes/ macrophages should be performed to elucidate the potential failure of this pathway in T1D pathogenesis.

\section{Implications of SIRPs:CD47 Signaling in T Cells and NK Cells in T1D}

While autoreactive $\mathrm{T}$ cells are widely accepted as a key pathogenic feature of insulitis in organ donors with T1D (67, 68), the role of NK cells in T1D pathogenesis remains somewhat controversial (69). Although NK cells have been observed to infiltrate the human pancreas during T1D pathogenesis, NK cells are not required for disease onset in the NOD mouse model (69, 70). Nevertheless, we hypothesize that T1D-associated SNPs in the SIRPG locus contribute towards the decrease of SIRP $\gamma$ expression on $\mathrm{T}$ cells and NK cells, potentially disrupting CD47 signaling and the downstream regulation that constrains the activation and proliferation of these subsets (Figure 2B). The impacts of T1D-associated SIRPG SNPs on T cell phenotype have been studied at the polyclonal level, but these observations must be validated in autoreactive islet-specific $T$ cell clones $(6,7)$. SIRP $\gamma^{\text {low }} \mathrm{CD}^{+} \mathrm{T}$ cells isolated from healthy human donors demonstrated an effector gene signature characterized by increased TBX21, EOMES, IFNG, and GZMB expression, and possessed lower activation thresholds, determined through antiCD3 titration in vitro, as compared to SIRP $\gamma^{\text {high }} \mathrm{CD}^{+} \mathrm{T}$ cells (6). These data support the hypothesis that decreased SIRP $\gamma$ expression may enhance $\mathrm{CD}^{+} \mathrm{T}$ cell-mediated $\beta$-cell destruction in T1D.

The ligation of CD47 is hypothesized to inhibit T and NK cell activation via inhibition of unknown elements downstream of the zeta chain of T cell receptor (TCR)-associated protein kinase 70 (ZAP70) activation and subsequent phosphorylation of the extracellular signal-regulated kinases (ERK) from the mitogenassociated protein kinase (MAPK) signaling cascade (Figure 2B) $(26,34-37)$. Indeed, while phosphorylation of ZAP70 was unaffected in activated Jurkat $\mathrm{T}$ cell lines incubated with the CD47 ligand TSP-1, TSP-1 inhibited activation-induced expression of $\mathrm{T}$ cell early activation markers, such as CD69 and early growth response gene-1 (EGR-1), demonstrating that CD47 could be acting downstream of ZAP70 to inhibit T cell activation (35). Additional studies have demonstrated that activation of CD47 inhibits $\mathrm{H}_{2} \mathrm{~S}$ signaling, which is a mediator of ERK signaling $(26,37)$. Thus, CD47 signaling is important in regulating $\mathrm{T}$ cell and potentially, $\mathrm{NK}$ cell activation through the MAPK pathway.

In contrast, however, one study found evidence that CD47 may instead promote the activation of $\mathrm{T}$ cells. Specifically, human Jurkat and primary human $\mathrm{T}$ cells or human CD47transfected murine 3.L2 T cells stimulated by anti-CD3 and antiCD47 activating antibodies, showed increased proliferation and IL-2 production as compared to those stimulated with anti-CD3 alone (71). Additionally, CD47 activation enhanced TCR zeta chain and ZAP70 phosphorylation (71). The cytoplasmic tail of CD47 was not necessary for these effects; rather, the membrane domain was required (71). The differing observations in this 
study (71) are thought to be due to activating antibodies eliciting a response from $\mathrm{CD} 47$ that contrasts from the quality or quantity of stimulation with TSP-1 in subsequent studies (26, 34-37). Thus, it is likely that endogenous CD47 signaling promotes T cell regulation; although, there are certainly unanswered questions regarding CD47 signaling in the context of other ligands.

Human tumor expression of CD47 has been shown to correlate with the expression of various co-inhibitory markers, such as program cell death protein 1 (PD-1) and cytotoxic Tlymphocyte associated protein 4 (CTLA-4), on tumor-infiltrating $\mathrm{CD}^{+}$and $\mathrm{CD}^{+} \mathrm{T}$ cells $(72,73)$. In mice, CD47 blockade contributed toward increased activation and cytotoxic potential of tumor-infiltrating $\mathrm{CD}^{+} \mathrm{T}$ cells $(72,73)$. Similarly, Seiffert et al. demonstrated that antibody-mediated blockade of either SIRP $\alpha$ or CD47 during DC priming of human $\mathrm{CD}^{+} \mathrm{T}$ cells reduced their anti-tumor cytotoxic activity in vitro (74). Disruption of SIRP $\alpha$ :CD47 signaling also increased NK cell activation and cytotoxicity while CD47 overexpression inhibited cytotoxic killing of tumor or MHC-deficient target cells in vitro; importantly, this latter observation was dependent upon $\operatorname{SIRP} \alpha$ expression on NK cells (32). These mechanistic studies are crucial to inform novel therapeutic approaches capable of differentially targeting the SIRP:CD47 signaling pathway in cancer and autoimmune disease settings.

It has also been observed that CD47 signaling can control thymocyte selection, memory $\mathrm{T}$ cell differentiation, and $\mathrm{CD} 4^{+} \mathrm{T}$ helper (Th) cell skewing $(25,26,41,55)$. Intriguingly, Dugas, et al. observed that a Cd47-deficient transgenic mouse model, expressing an anti-hen egg lysozyme (HEL) TCR (clone 3A9) and HEL under the insulin promoter on the BALB/H-2k background, developed accelerated autoimmune diabetes concomitantly with a roughly two to four-fold decrease of regulatory $\mathrm{CD}^{-} \mathrm{CD}^{-}$double negative $(\mathrm{DN}) \mathrm{T}$ cells in the spleen and skin-draining lymph nodes compared to Cd47sufficient controls (55). Briefly, DN T cells express a TCR but not CD4, CD8 or NK markers, and they exert antigen-specific negative regulation over effector $\mathrm{T}$ cells within peripheral blood (75). In the NOD model, DN T cells have been shown to prevent diabetes via production of IL-10 and/or cytotoxicity toward antigen-specific B cells $(76,77)$, regulatory mechanisms which may be lacking in the absence of CD47 expression. Meanwhile, defects in peripheral regulation may also be attributed to the loss of CD47-dependent $\mathrm{T}$ cell killing in the periphery (25).

Increased CD47 expression has been observed on naïve and central memory as compared to effector memory $\mathrm{CD} 4^{+} \mathrm{T}$ cells (Figure 2C) (41-43). CD47 expression is lower on activated than long-lived antigen-specific memory $\mathrm{CD}^{+} \mathrm{T}$ cells (41). When $\mathrm{CD}^{+} \mathrm{T}$ cells exhibit low CD47 expression, skewing shifts from a Th2 phenotype toward an inflammatory Th1 response (42). Together, these studies suggest that disruption of CD47 signaling could potentially augment $\mathrm{T}$ cell cytotoxicity and infiltration into pancreatic tissues while inhibiting regulatory $\mathrm{T}$ cell-mediated protection against $\beta$-cell destruction in T1D (Figure 3).

Interestingly, NOD mice carry a polymorphism in the Sirp $\alpha$ gene that induces an 18 amino acid variation in the $\operatorname{IgV}$-like domain of the SIRP $\alpha$ protein, as compared to the non-obese diabetes resistant (NOR) strain (56). This variation was determined to increase the binding of $\operatorname{SIRP} \alpha$ to $\mathrm{CD} 47$, thus increasing SIRP $\alpha$ :CD47 signaling between APCs and T cells (56). Furthermore, the authors showed that diabetogenic NOD.BDC2.5 $\mathrm{CD}^{+} \mathrm{T}$ cells exhibited increased proliferation and lower activation thresholds when co-cultured with NOD DCs with increased SIRP $\alpha$ binding, as compared to NOR DCs with decreased SIRP $\alpha$ binding to CD47 (56). More studies are required to understand how SIRPs:CD47 signaling affects priming and activation of $\mathrm{CD}^{+}$and $\mathrm{CD}^{+} \mathrm{T}$ cells, and the corresponding implications for $\mathrm{T}$ cell-mediated autoimmunity and T1D pathogenesis.

SIRPG does not have an orthologous counterpart in the mouse, limiting studies of this gene in vivo. In an in vitro coculture model of human T cells and TNF- $\alpha$ activated human umbilical vein endothelial cell (HUVEC) monolayers under shear flow conditions, anti-CD47 and anti-SIRP $\gamma$ antibodies prevented $\mathrm{T}$ cell transmigration across HUVECs $(39,40)$. Similarly, these authors observed a decrease in in vitro transendothelial migration of $\mathrm{T}$ cells across murine heart endothelial cell (MHEC) monolayers from CD47/- C57BL/6 mice in the presence of TNF- $\alpha$ induced inflammation $(39,40)$. Therefore, CD47 binding to SIRP $\alpha$ or SIRP $\gamma$ can presumably alter $\mathrm{T}$ cell extravasation (Figure 2C). Whether SIRP $\gamma$ :CD47 binding during transmigration is associated with modulation of $\mathrm{T}$ or NK cell activation remains of interest. These in vitro observations warrant further investigation of how SIRP $\gamma: C D 47$ signaling might play a role in modifying cell migration using ex vivo platforms to study human pancreas (78-80) samples or humanized mouse models (81) xenografted with human cells to explore potential implications for islet infiltration and the development of insulitis in human T1D.

\section{Implications of SIRP $\alpha: C D 47$ Signaling in Pancreatic $\beta$-Cells in T1D}

Previous literature examining the impact of SIRP:CD47 signaling has primarily focused on host immunity in the context of cancer development; hence, little is currently known about how this pathway relates to pancreatic $\beta$-cell development and survival in the context of T1D pathogenesis. CD47 forms clusters in lipid rafts on the surface of healthy cells, facilitating SIRP $\alpha$ ligation to inhibit phagocytosis by macrophages; in contrast, apoptotic cells exhibit a diffuse surface distribution of CD47 reducing the "don't eat me" signal (82). Hence, in pancreatic $\beta$-cells, CD47 is hypothesized to promote survival via propagation of the "don't eat me" signal in addition to regulating calcium $\left(\mathrm{Ca}^{2+}\right)$ signaling associated with protection afforded by autophagy (Figure 3) (29, $30,34,45)$. CD47 promotes survival signaling through induction of the activator protein 1 (AP-1) transcriptional factor family, including the Jun (c-Jun, JunB, and Jun D) subset of transcription factors, in a majority of endothelial tissues and including $\beta$-cells (83-85). CD47 also enhances intracellular $\mathrm{Ca}^{2+}$ flux, which in terms of $\beta$-cell functionality, can contribute towards promoting cell adhesion along with triggering insulin secretion $(86,87)$. BNIP3 is bound to the cytoplasmic tail of 
CD47, where it can interact with Beclin-1, promoting protective autophagy through the unfolded protein response (UPR) which may occur in stressed $\beta$-cells $(34,38)$. Independent of immunemediated destruction, SNPs tagged to genes involved in the regulation of apoptosis (protein tyrosine phosphatase nonreceptor 2 (PTPN2): rs1893217 and tumor necrosis factor, alpha-induced protein 3 (TNFAIP3): rs2327832) have been associated with $\mathrm{T} 1 \mathrm{D}$, with the risk variants resulting in increased apoptosis of $\beta$-cells $(88,89)$. Accordingly, we hypothesize that CD47 expression level or distribution may be altered on the surface of $\beta$-cells in individuals carrying risk alleles for these anti-apoptotic genes, thereby impacting $\beta$-cell survival.

Additionally, SIRP $\alpha$ is hypothesized to upregulate insulin secretion and/or production (Figure 3) (29, 31, 44, 54). Expression of SIRP $\alpha$ and CD47 colocalize with insulin staining in $\beta$-cells of C57BL/6 mice (29). High-fat diet-fed SIRP $\alpha^{-/-}$mice exhibit reduced plasma insulin levels and impaired glucose tolerance as compared to wild-type mice, providing in vivo evidence that SIRP $\alpha$ can control insulin secretion in the context of metabolic stress (29). SIRP $\alpha$ phosphorylation is stimulated by insulin and insulin-like growth factor-1 (IGF-1); therefore, it is thought that $\operatorname{SIRP} \alpha$ activation is controlled contemporaneously with insulin/IGF-1 receptor signaling (29, 90). This last observation is intriguing as we recently reported that IGF-1 levels are deficient before the clinical onset of T1D in at-risk subjects (91), potentially contributing to a decrease in SIRP $\alpha$ signaling in $\beta$-cells. The interaction between SIRP $\alpha$ and CD47, expressed on both APCs and pancreatic $\beta$-cells, might represent a key factor in T1D pathogenesis, and studies are warranted to examine their in situ expression in the human pancreas from control and T1D donors, impact on insulin production, and eQTL epistasis from single-cell sequencing data (92).

\section{POTENTIAL FOR SIRP:CD47- MODULATING THERAPEUTICS IN T1D}

Strategies focused on restoring or monitoring SIRP $\alpha$, SIRP $\gamma$, and/or CD47 expression in subjects at-risk or with recent T1D onset may aid in the prediction, prevention or reversal of T1D. The SIRPG T1D-risk alleles and other T1D-risk loci have been associated with serological markers of disease progression. For example, a study conducted by The Environmental Determinants of Diabetes in the Young (TEDDY) consortium found that among individuals with the high-risk HLA-DR3/4 genotype, the minor (protective) allele for rs2281808 reduced the risk of islet autoantibody (AAb) seroconversion as compared to the major (risk) allele (93). These analyses suggest that SIRPG SNP genotypes may associate with highrisk HLA diplotypes, thus reinforcing the importance of examining the roles of both HLA and non-HLA risk SNPs in modulating events driving tissue-specific reactivity in the pathogenesis of T1D (93).

In individuals with a family history of T1D or islet $\mathrm{AAb}$ seropositivity, SIRPG SNP genotyping could potentially allow for the identification of individuals who may benefit from SIRP:CD47 modulating therapies in precision medicine applications. Indeed, small molecule drugs or biologics that promote SIRPG expression or SIRP $\gamma: C D 47$ signaling could serve as novel candidate therapies. Those that target CD47 (e.g., CD47 activating antibodies or SIRP $\gamma$ : CD47 bi-specific antibodies) would likely be preferable for two key reasons: 1) SIRP $\gamma: C D 47$ signaling occurs unilaterally downstream of CD47, and 2) the T1D-risk associated SNPs tagged to SIRPG are predicted to promote reduced SIRP $\gamma$ expression and/or interaction with $\operatorname{CD} 47(5,6,20,31,35)$. Additionally, upregulation of CD47 and/or SIRP $\alpha$ expression on induced pluripotent stem cell-derived $\beta$-cells or islet transplants might augment their survival following $\beta$-cell replacement therapy in persons with longstanding T1D (Figure 4).

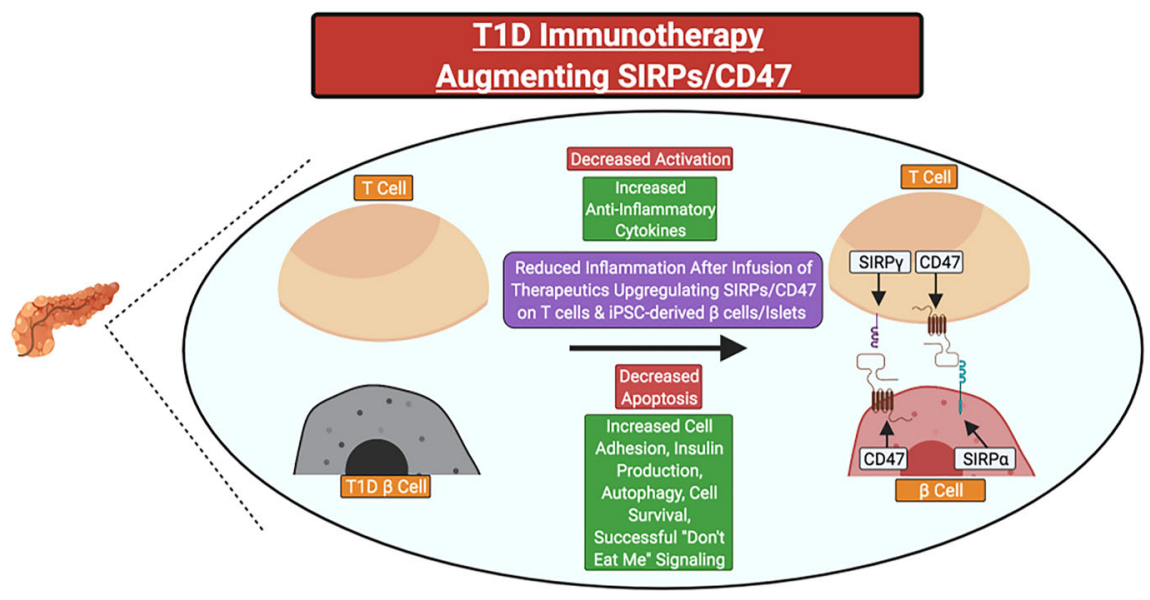

FIGURE 4 | Potential clinical therapeutics targeting SIRPs and CD47 for type 1 diabetes prevention or suspension. Immunotherapies could be utilized to increase the expression of SIRP $\gamma$ and/or CD47 on primary T cells for adoptive cell therapies or CD47 on stem cell-derived $\beta$-cells or islets before transplant to attenuate the magnitude of recurrent autoimmunity. Red Text Box: Expected Decrease; Green Text Box: Expected Increase. 
We hypothesize that SIRP $\gamma$ expression on immune cells may be correlated with specific stages of T1D development in a manner governed by genetic risk variants in SIRPG, and thus, could be used as a biomarker of disease progression in conjunction with $\mathrm{C}$ peptide and AAbs $(12,93,94)$. In T1D subjects, SIRPG SNP genotype was associated with T1D risk at an early age ( $P$-value $<0.05$, unadjusted), with the greatest effect at $<7$ years of age, an intermediate impact from 7 to 13 years of age, and a reduced impact at $>13$ years of age; therefore, therapeutic approaches involving SIRPG may have the highest efficacy at delaying or reducing T1D onset in younger patients $(12,93,94)$.

\section{DISCUSSION/CONCLUSION}

As reviewed herein, prior research has suggested that SIRPs and CD47 could be involved in immunoregulation and cross-talk between immune cells as well as able to protect cells from targeted cellular destruction. However, it remains unclear how SIRP:CD47 signaling affects $\mathrm{T}$ cell activation in the periphery. We hypothesize that SIRP:CD47 represents a co-inhibitory pathway involved in immunoregulation. Because autoreactive $\mathrm{T}$ cells that bypass negative selection in the thymus are thought to express lower TCR affinities, SIRP:CD47 signaling may have an important effect on both central and peripheral tolerance during autoimmune disease pathogenesis. Therefore, we propose that novel immunotherapies that upregulate the expression of SIRP $\gamma$ on T cells or increase CD47 signaling in persons with recent-onset or pre-T1D could ultimately serve as a powerful therapeutic approach to inhibit autoimmune destruction. However, additional research, including genotype/phenotype population studies, novel gene and SNP editing approaches, and longitudinal natural history studies are required to determine if the SIRP:CD47 signaling pathway could serve as an informative predictive biomarker of this disease or viable target for immune modulation.

\section{REFERENCES}

1. Inshaw JRJ, Cutler AJ, Crouch DJM, Wicker LS, Todd JA. Genetic Variants Predisposing Most Strongly to Type 1 Diabetes Diagnosed Under Age 7 Years Lie Near Candidate Genes That Function in the Immune System and in Pancreatic $\beta$ Cells. Diabetes Care (2020) 43(1):169-77. doi: 10.2337/dc19-0803

2. Kawabata Y, Ikegami H. Genetics of Fulminant Type 1 Diabetes. Diabetol Int (2020) 11(4):315-22. doi: 10.1007/s13340-020-00468-0

3. Pang H, Luo S, Huang G, Xia Y, Xie Z, Zhou Z. Advances in Knowledge of Candidate Genes Acting at the Beta-Cell Level in the Pathogenesis of T1DM. Front Endocrinol (Lausanne) (2020) 11:119. doi: 10.3389/fendo.2020.00119

4. Robertson CC, Inshaw JRJ, Onengut-Gumuscu S, Chen WM, Cruz DFS, Yang $\mathrm{H}$, et al. Fine-Mapping, Trans-Ancestral and Genomic Analyses Identify Causal Variants, Cells, Genes and Drug Targets for Type 1 Diabetes. bioRxiv (2020) 53:(7):962-71. doi: 10.1038/s41588-021-00880-5

5. Nettleship JE, Ren J, Scott DJ, Rahman N, Hatherley D, Zhao Y, et al. Crystal Structure of Signal Regulatory Protein Gamma (Sirp $\gamma$ ) in Complex With an Antibody Fab Fragment. BMC Struct Biol (2013) 13:13. doi: 10.1186/14726807-13-13

6. Sinha S, Borcherding N, Renavikar PS, Crawford MP, Tsalikian E, Tansey M, et al. An Autoimmune Disease Risk SNP, Rs2281808, in SIRPG Is Associated

\section{AUTHOR CONTRIBUTIONS}

RCS: Conceptualization, Investigation, Writing-Original Draft, Visualization. MEB: Conceptualization, Investigation, WritingOriginal Draft, Visualization. MRS: Investigation, WritingReview and Editing. ALP: Investigation, Writing-Review and Editing. TMB: Writing-Review and Editing, Supervision, Project Administration, Funding Acquisition. All authors contributed to the article and approved the submitted version.

\section{FUNDING}

Efforts related to the content reviewed herein are supported by grants from the National Institutes of Health NIAID (P01 AI042288 to TMB), NIDDK Human Islet Research Network (HIRN; UG3 DK122638 to TMB), the University of Florida (UF) Experimental Pathology Innovation Grant (EPIG; 2908EPIG to RCS), HIRN Emerging Leaders in T1D (Human Islet Research Enhancement Center (HIREC) U24 DK104162 to RCS), and The Leona M. \& Harry B. Helmsley Charitable Trust (Grant\# 2018PG-T1D071 and Grant\# 2004-03813 to TMB). Research related to this Review was also supported by the Network for Pancreatic Organ donors with Diabetes (nPOD; RRID : SCR_014541), a collaborative type 1 diabetes research project sponsored by JDRF (nPOD:5-SRA-2018-557-Q-R, 25-2013-268, 25-2012-380, and 25-2007-874 to MAA) and The Leona M. \& Harry B. Helmsley Charitable Trust (Grant\# 2018PG-T1D053).

\section{ACKNOWLEDGMENTS}

The authors would like to thank members of the TB lab and the University of Florida Diabetes Institute for helpful discussions. Figures were created with BioRender.com.
With Reduced Expression of Sirpy and Heightened Effector State in Human CD8 T-Cells. Sci Rep (2018) 8(1):15440. doi: 10.1038/s41598-018-33901-1

7. Sinha S, Renavikar PS, Crawford MP, Rodgers JW, Tsalikian E, Tansey M, et al. Autoimmunity-Associated Intronic SNP (Rs2281808) Detected by a Simple Phenotypic Assay: Unique Case or Broader Opportunity? Clin Immunol (2019) 198:57-61. doi: 10.1016/j.clim.2018.12.018

8. Barrett JC, Clayton DG, Concannon P, Akolkar B, Cooper JD, Erlich HA, et al. Genome-Wide Association Study and Meta-Analysis Find That Over 40 Loci Affect Risk of Type 1 Diabetes. Nat Genet (2009) 41(6):703-7. doi: $10.1038 /$ ng.381

9. Buniello A, MacArthur JAL, Cerezo M, Harris LW, Hayhurst J, Malangone C, et al. The NHGRI-EBI GWAS Catalog of Published Genome-Wide Association Studies, Targeted Arrays and Summary Statistics 2019. Nucleic Acids Res (2019) 47(D1):D1005-12. doi: 10.1093/nar/gky1120

10. Kiani AK, Jahangir S, Jahngir S, John P, Bhatti A, Zia A, et al. Genetic Link of Type 1 Diabetes Susceptibility Loci With Rheumatoid Arthritis in Pakistani Patients. Immunogenetics (2015) 67(5-6):277-82. doi: 10.1007/s00251-0150839-0

11. Kiani AK, John P, Bhatti A, Zia A, Shahid G, Akhtar P, et al. Association of 32 Type 1 Diabetes Risk Loci in Pakistani Patients. Diabetes Res Clin Pract (2015) 108(1):137-42. doi: 10.1016/j.diabres.2015.01.022 
12. Reddy MV, Wang H, Liu S, Bode B, Reed JC, Steed RD, et al. Association Between Type 1 Diabetes and GWAS SNPs in the Southeast US Caucasian Population. Genes Immun (2011) 12(3):208-12. doi: 10.1038/gene.2010.70

13. Machiela MJ, Chanock SJ. LDlink: A Web-Based Application for Exploring Population-Specific Haplotype Structure and Linking Correlated Alleles of Possible Functional Variants. Bioinformatics (2015) 31(21):3555-7. doi: 10.1093/bioinformatics/btv402

14. Onengut-Gumuscu S, Chen WM, Burren O, Cooper NJ, Quinlan AR, Mychaleckyj JC, et al. Fine Mapping of Type 1 Diabetes Susceptibility Loci and Evidence for Colocalization of Causal Variants With Lymphoid Gene Enhancers. Nat Genet (2015) 47(4):381-6. doi: 10.1038/ng.3245

15. Westra HJ, Martínez-Bonet M, Onengut-Gumuscu S, Lee A, Luo Y, Teslovich $\mathrm{N}$, et al. Fine-Mapping and Functional Studies Highlight Potential Causal Variants for Rheumatoid Arthritis and Type 1 Diabetes. Nat Genet (2018) 50 (10):1366-74. doi: 10.1038/s41588-018-0216-7

16. de Lange KM, Moutsianas L, Lee JC, Lamb CA, Luo Y, Kennedy NA, et al. Genome-Wide Association Study Implicates Immune Activation of Multiple Integrin Genes in Inflammatory Bowel Disease. Nat Genet (2017) 49(2):25661. doi: $10.1038 /$ ng. 3760

17. Liu JZ, van Sommeren S, Huang H, Ng SC, Alberts R, Takahashi A, et al. Association Analyses Identify 38 Susceptibility Loci for Inflammatory Bowel Disease and Highlight Shared Genetic Risk Across Populations. Nat Genet (2015) 47(9):979-86. doi: 10.1038/ng.3359

18. National Center for Biotechnology Information (NCBI). Bethesda (MD): National Library of Medicine (US), National Center for Biotechnology Information (1988). Available at: https://www.ncbi.nlm.nih.gov.

19. Li J, Comeau HY, Zhang Z, Ren X. Landscape of Transcript Isoforms in Single T Cells Infiltrating in Non-Small-Cell Lung Cancer. J Genet Genomics (2020) 47(7):373-88. doi: 10.1016/j.jgg.2020.06.006

20. Anna A, Monika G. Splicing Mutations in Human Genetic Disorders: Examples, Detection, and Confirmation. J Appl Genet (2018) 59(3):253-68. doi: 10.1007/s13353-018-0444-7

21. Carvalho-Silva D, Pierleoni A, Pignatelli M, Ong C, Fumis L, Karamanis N, et al. Open Targets Platform: New Developments and Updates Two Years On. Nucleic Acids Res (2019) 47(D1):D1056-65. doi: 10.1093/nar/gky1133

22. Brooke G, Holbrook JD, Brown MH, Barclay AN. Human Lymphocytes Interact Directly With CD47 Through a Novel Member of the Signal Regulatory Protein (SIRP) Family. J Immunol (2004) 173(4):2562-70. doi: 10.4049/jimmunol.173.4.2562

23. Brown EJ, Frazier WA. Integrin-Associated Protein (CD47) and Its Ligands. Trends Cell Biol (2001) 11(3):130-5. doi: 10.1016/s0962-8924(00)01906-1

24. Lamy L, Ticchioni M, Rouquette-Jazdanian AK, Samson M, Deckert M, Greenberg AH, et al. CD47 and the $19 \mathrm{kDa}$ Interacting Protein-3 (BNIP3) in T Cell Apoptosis. J Biol Chem (2003) 278(26):23915-21. doi: 10.1074/ jbc.M301869200

25. Manna PP, Frazier WA. The Mechanism of CD47-Dependent Killing of T Cells: Heterotrimeric Gi-Dependent Inhibition of Protein Kinase A. J Immunol (2003) 170(7):3544-53. doi: 10.4049/jimmunol.170.7.3544

26. Miller TW, Kaur S, Ivins-O'Keefe K, Roberts DD. Thrombospondin-1 Is a CD47-Dependent Endogenous Inhibitor of Hydrogen Sulfide Signaling in T Cell Activation. Matrix Biol (2013) 32(6):316-24. doi: 10.1016/ j.matbio.2013.02.009

27. Nath PR, Gangaplara A, Pal-Nath D, Mandal A, Maric D, Sipes JM, et al. CD47 Expression in Natural Killer Cells Regulates Homeostasis and Modulates Immune Response to Lymphocytic Choriomeningitis Virus. Front Immunol (2018) 9:2985. doi: 10.3389/fimmu.2018.02985

28. Nath PR, Pal-Nath D, Mandal A, Cam MC, Schwartz AL, Roberts DD. Natural Killer Cell Recruitment and Activation Are Regulated by CD47 Expression in the Tumor Microenvironment. Cancer Immunol Res (2019) 7 (9):1547-61. doi: 10.1158/2326-6066.CIR-18-0367

29. Kobayashi M, Ohnishi H, Okazawa H, Murata Y, Hayashi Y, Kobayashi H, et al. Expression of Src Homology 2 Domain-Containing Protein Tyrosine Phosphatase Substrate-1 in Pancreatic Beta-Cells and Its Role in Promotion of Insulin Secretion and Protection Against Diabetes. Endocrinology (2008) 149 (11):5662-9. doi: 10.1210/en.2008-0236

30. Zhang SS, Hao E, Yu J, Liu W, Wang J, Levine F, et al. Coordinated Regulation by Shp2 Tyrosine Phosphatase of Signaling Events Controlling Insulin
Biosynthesis in Pancreatic Beta-Cells. Proc Natl Acad Sci USA (2009) 106 (18):7531-6. doi: 10.1073/pnas.0811715106

31. Barclay AN, Van den Berg TK. The Interaction Between Signal Regulatory Protein Alpha (Sirp $\alpha)$ and CD47: Structure, Function, and Therapeutic Target. Annu Rev Immunol (2014) 32:25-50. doi: 10.1146/annurevimmunol-032713-120142

32. Deuse T, Hu X, Agbor-Enoh S, Jang MK, Alawi M, Saygi C, et al. The SirpoCD47 Immune Checkpoint in NK Cells. J Exp Med (2021) 218(3):e20200839. doi: 10.1084/jem.20200839

33. Frazier WA, Gao AG, Dimitry J, Chung J, Brown EJ, Lindberg FP, et al. The Thrombospondin Receptor Integrin-Associated Protein (CD47) Functionally Couples to Heterotrimeric Gi. J Biol Chem (1999) 274(13):8554-60. doi: $10.1074 / j b c .274 .13 .8554$

34. Soto-Pantoja DR, Kaur S, Roberts DD. CD47 Signaling Pathways Controlling Cellular Differentiation and Responses to Stress. Crit Rev Biochem Mol Biol (2015) 50(3):212-30. doi: 10.3109/10409238.2015.1014024

35. Li Z, He L, Wilson K, Roberts D. Thrombospondin-1 Inhibits TCR-Mediated T Lymphocyte Early Activation. J Immunol (2001) 166(4):2427-36. doi: 10.4049/jimmunol.166.4.2427

36. Shinohara M, Ohyama N, Murata $\mathrm{Y}$, Okazawa $\mathrm{H}$, Ohnishi $\mathrm{H}$, Ishikawa $\mathrm{O}$, et al. CD47 Regulation of Epithelial Cell Spreading and Migration, and Its Signal Transduction. Cancer Sci (2006) 97(9):889-95. doi: 10.1111/j.1349-7006.2006.00245.x

37. Wang XQ, Lindberg FP, Frazier W. A. Integrin-Associated Protein Stimulates Alpha2beta1-Dependent Chemotaxis via Gi-Mediated Inhibition of Adenylate Cyclase and Extracellular-Regulated Kinases. J Cell Biol (1999) 147(2):389-400. doi: 10.1083/jcb.147.2.389

38. Chen ZF, Li YB, Han JY, Wang J, Yin JJ, Li JB, et al. The Double-Edged Effect of Autophagy in Pancreatic Beta Cells and Diabetes. Autophagy (2011) 7 (1):12-6. doi: 10.4161/auto.7.1.13607

39. Azcutia V, Stefanidakis M, Tsuboi N, Mayadas T, Croce KJ, Fukuda D, et al. Endothelial CD47 Promotes Vascular Endothelial-Cadherin Tyrosine Phosphorylation and Participates in T Cell Recruitment at Sites of Inflammation In Vivo. J Immunol (2012) 189(5):2553-62. doi: 10.4049/ jimmunol.1103606

40. Stefanidakis M, Newton G, Lee WY, Parkos CA, Luscinskas FW. Endothelial CD47 Interaction With SIRPgamma Is Required for Human T-Cell Transendothelial Migration Under Shear Flow Conditions. Vitro Blood (2008) 112(4):1280-9. doi: 10.1182/blood-2008-01-134429

41. Van VQ, Raymond M, Baba N, Rubio M, Wakahara K, Susin SA, et al. CD47 (high) Expression on CD4 Effectors Identifies Functional Long-Lived Memory T Cell Progenitors. J Immunol (2012) 188(9):4249-55. doi: 10.4049/ jimmunol.1102702

42. Hayat SMG, Bianconi V, Pirro M, Jaafari MR, Hatamipour M, Sahebkar A. CD47: Role in the Immune System and Application to Cancer Therapy. Cell Oncol (Dordr) (2020) 43(1):19-30. doi: 10.1007/s13402019-00469-5

43. Legrand N, Huntington ND, Nagasawa M, Bakker AQ, Schotte R, StrickMarchand H, et al. Functional CD47/signal Regulatory Protein Alpha (SIRP (alpha)) Interaction Is Required for Optimal Human T- and Natural Killer(NK) Cell Homeostasis In Vivo. Proc Natl Acad Sci USA (2011) 108 (32):13224-9. doi: 10.1073/pnas.1101398108

44. Matozaki T, Murata Y, Okazawa H, Ohnishi H. Functions and Molecular Mechanisms of the CD47-SIRPalpha Signalling Pathway. Trends Cell Biol (2009) 19(2):72-80. doi: 10.1016/j.tcb.2008.12.001

45. Kaur S, Roberts DD. Divergent Modulation of Normal and Neoplastic Stem Cells by Thrombospondin-1 and CD47 Signaling. Int J Biochem Cell Biol (2016) 81(Pt A):184-94. doi: 10.1016/j.biocel.2016.05.005

46. Espinoza-Jiménez A, Peón AN, Terrazas LI. Alternatively Activated Macrophages in Types 1 and 2 Diabetes. Mediat Inflamm (2012) 2012:815953. doi: $10.1155 / 2012 / 815953$

47. Hotta-Iwamura C, Tarbell KV. Type 1 Diabetes Genetic Susceptibility and Dendritic Cell Function: Potential Targets for Treatment. J Leukoc Biol (2016) 100(1):65-80. doi: 10.1189/jlb.3MR1115-500R

48. Zhang M, Hutter G, Kahn SA, Azad TD, Gholamin S, Xu CY, et al. Anti-CD47 Treatment Stimulates Phagocytosis of Glioblastoma by M1 and M2 Polarized Macrophages and Promotes M1 Polarized Macrophages In Vivo. PloS One (2016) 11(4):e0153550. doi: 10.1371/journal.pone.0153550 
49. Aamodt KI, Powers AC. Signals in the Pancreatic Islet Microenvironment Influence $\beta$-Cell Proliferation. Diabetes Obes Metab (2017) 19(Suppl 1):12436. doi: 10.1111/dom.13031

50. Brissova M, Aamodt K, Brahmachary P, Prasad N, Hong JY, Dai C, et al. Islet Microenvironment, Modulated by Vascular Endothelial Growth Factor-A Signaling, Promotes $\beta$ Cell Regeneration. Cell Metab (2014) 19(3):498-511. doi: 10.1016/j.cmet.2014.02.001

51. Saunders D, Powers AC. Replicative Capacity of $\beta$-Cells and Type 1 Diabetes. J Autoimmun (2016) 71:59-68. doi: 10.1016/j.jaut.2016.03.014

52. Wang YJ, Traum D, Schug J, Gao L, Liu C, Atkinson MA, et al. Multiplexed In Situ Imaging Mass Cytometry Analysis of the Human Endocrine Pancreas and Immune System in Type 1 Diabetes. Cell Metab (2019) 29(3):769783.e764. doi: 10.1016/j.cmet.2019.01.003

53. Xiao X, Gaffar I, Guo P, Wiersch J, Fischbach S, Peirish L, et al. M2 Macrophages Promote Beta-Cell Proliferation by Up-Regulation of SMAD7. Proc Natl Acad Sci USA (2014) 111(13):E1211-1220. doi: 10.1073/pnas. 1321347111

54. Zhang J, Tan SB, Guo ZG. CD47 Decline in Pancreatic Islet Cells Promotes Macrophage-Mediated Phagocytosis in Type I Diabetes. World J Diabetes (2020) 11(6):239-51. doi: 10.4239/wjd.v11.i6.239

55. Dugas V, Beauchamp C, Chabot-Roy G, Hillhouse EE, Lesage S. Implication of the CD47 Pathway in Autoimmune Diabetes. J Autoimmun (2010) 35 (1):23-32. doi: 10.1016/j.jaut.2010.01.002

56. Wong AS, Mortin-Toth S, Sung M, Canty AJ, Gulban O, Greaves DR, et al. Polymorphism in the Innate Immune Receptor Sirp $\alpha$ Controls CD47 Binding and Autoimmunity in the Nonobese Diabetic Mouse. J Immunol (2014) 193 (10):4833-44. doi: 10.4049/jimmunol.1401984

57. Hayes BH, Tsai RK, Dooling LJ, Kadu S, Lee JY, Pantano D, et al. Macrophages Show Higher Levels of Engulfment After Disruption of. J Cell Sci (2020) 133(5):jcs237800. doi: 10.1242/jcs.237800

58. Tal MC, Torrez Dulgeroff LB, Myers L, Cham LB, Mayer-Barber KD, Bohrer AC, et al. Upregulation of CD47 Is a Host Checkpoint Response to Pathogen Recognition. mBio (2020) 11(3):e01293-20. doi: 10.1128/mBio.01293-20

59. Weiskopf K, Jahchan NS, Schnorr PJ, Cristea S, Ring AM, Maute RL, et al. CD47-Blocking Immunotherapies Stimulate Macrophage-Mediated Destruction of Small-Cell Lung Cancer. J Clin Invest (2016) 126(7):2610-20. doi: 10.1172/JCI81603

60. Demeure CE, Tanaka H, Mateo V, Rubio M, Delespesse G, Sarfati M. CD47 Engagement Inhibits Cytokine Production and Maturation of Human Dendritic Cells. J Immunol (2000) 164(4):2193-9. doi: 10.4049/ jimmunol.164.4.2193

61. Lin Y, Zhao JL, Zheng QJ, Jiang X, Tian J, Liang SQ, et al. Notch Signaling Modulates Macrophage Polarization and Phagocytosis Through Direct Suppression of Signal Regulatory Protein $\alpha$ Expression. Front Immunol (2018) 9:1744. doi: 10.3389/fimmu.2018.01744

62. Zhang Y, Sime W, Juhas M, Sjölander A. Crosstalk Between Colon Cancer Cells and Macrophages via Inflammatory Mediators and CD47 Promotes Tumour Cell Migration. Eur J Cancer (2013) 49(15):3320-34. doi: 10.1016/ j.ejca.2013.06.005

63. Tseng D, Volkmer JP, Willingham SB, Contreras-Trujillo H, Fathman JW, Fernhoff NB, et al. Anti-CD47 Antibody-Mediated Phagocytosis of Cancer by Macrophages Primes an Effective Antitumor T-Cell Response. Proc Natl Acad Sci USA (2013) 110(27):11103-8. doi: 10.1073/pnas.1305569110

64. Cham LB, Adomati T, Li F, Ali M, Lang KS. CD47 as a Potential Target to Therapy for Infectious Diseases. Antibodies (Basel) (2020) 9(3):44. doi: 10.3390/antib9030044

65. Oldenborg PA, Gresham HD, Chen Y, Izui S, Lindberg FP. Lethal Autoimmune Hemolytic Anemia in CD47-Deficient Nonobese Diabetic (NOD) Mice. Blood (2002) 99(10):3500-4. doi: 10.1182/blood.v99.10.3500

66. Bian Z, Shi L, Guo YL, Lv Z, Tang C, Niu S, et al. Cd47-Sirpo Interaction and IL-10 Constrain Inflammation-Induced Macrophage Phagocytosis of Healthy Self-Cells. Proc Natl Acad Sci USA (2016) 113(37):E5434-43. doi: 10.1073/ pnas. 1521069113

67. Burrack AL, Martinov T, Fife BT. T Cell-Mediated Beta Cell Destruction: Autoimmunity and Alloimmunity in the Context of Type 1 Diabetes. Front Endocrinol (Lausanne) (2017) 8:343. doi: 10.3389/fendo.2017.00343

68. Pugliese A. Autoreactive T Cells in Type 1 Diabetes. J Clin Invest (2017) 127 (8):2881-91. doi: 10.1172/JCI94549
69. Marca V, Gianchecchi E, Fierabracci A. Type 1 Diabetes and Its MultiFactorial Pathogenesis: The Putative Role of NK Cells. Int J Mol Sci (2018) 19 (3):794. doi: 10.3390/ijms19030794

70. Kataoka S, Satoh J, Fujiya H, Toyota T, Suzuki R, Itoh K, et al. Immunologic Aspects of the Nonobese Diabetic (NOD) Mouse. Abnormalities of Cellular Immunity. Diabetes (1983) 32(3):247-53. doi: 10.2337/diab.32.3.247

71. Reinhold MI, Lindberg FP, Kersh GJ, Allen PM, Brown EJ. Costimulation of T Cell Activation by Integrin-Associated Protein (CD47) Is an AdhesionDependent, CD28-Independent Signaling Pathway. J Exp Med (1997) 185 (1):1-11. doi: 10.1084/jem.185.1.1

72. Schwartz AL, Nath PR, Allgauer M, Lessey-Morillon EC, Sipes JM, Ridnour LA, et al. Antisense Targeting of CD47 Enhances Human Cytotoxic T-Cell Activity and Increases Survival of Mice Bearing B16 Melanoma When Combined With Anti-CTLA4 and Tumor Irradiation. Cancer Immunol Immunother (2019) 68(11):1805-17. doi: 10.1007/s00262-019-02397-7

73. Wu L, Yu GT, Deng WW, Mao L, Yang LL, Ma SR, et al. Anti-CD47 Treatment Enhances Anti-Tumor T-Cell Immunity and Improves Immunosuppressive Environment in Head and Neck Squamous Cell Carcinoma. Oncoimmunology (2018) 7(4):e1397248. doi: 10.1080/21624 02X.2017.1397248

74. Seiffert M, Brossart P, Cant C, Cella M, Colonna M, Brugger W, et al. SignalRegulatory Protein Alpha (SIRPalpha) But Not SIRPbeta Is Involved in T-Cell Activation, Binds to CD47 With High Affinity, and Is Expressed on Immature CD34(+)CD38(-) Hematopoietic Cells. Blood (2001) 97(9):2741-9. doi: 10.1182/blood.v97.9.2741

75. Juvet SC, Zhang L. Double Negative Regulatory T Cells in Transplantation and Autoimmunity: Recent Progress and Future Directions. J Mol Cell Biol (2012) 4(1):48-58. doi: 10.1093/jmcb/mjr043

76. Duncan B, Nazarov-Stoica C, Surls J, Kehl M, Bona C, Casares S, et al. Double Negative (CD3+ 4- 8-) TCR Alphabeta Splenic Cells From Young NOD Mice Provide Long-Lasting Protection Against Type 1 Diabetes. PloS One (2010) 5 (7):e11427. doi: 10.1371/journal.pone.0011427

77. Hillhouse EE, Beauchamp C, Chabot-Roy G, Dugas V, Lesage S. Interleukin10 Limits the Expansion of Immunoregulatory CD4-CD8- T Cells in Autoimmune-Prone Non-Obese Diabetic Mice. Immunol Cell Biol (2010) 88(8):771-80. doi: 10.1038/icb.2010.84

78. Huber MK, Drotar DM, Hiller H, Beery ML, Joseph P, Kusmartseva I, et al. Observing Islet Function and Islet-Immune Cell Interactions in Live Pancreatic Tissue Slices. J Vis Exp (2021) 170:10.3791/62207. doi: 10.3791/ 62207

79. Jiang K, Chaimov D, Patel SN, Liang JP, Wiggins SC, Samojlik MM, et al. 3-D Physiomimetic Extracellular Matrix Hydrogels Provide a Supportive Microenvironment for Rodent and Human Islet Culture. Biomaterials (2019) 198:37-48. doi: 10.1016/j.biomaterials.2018.08.057

80. Panzer JK, Hiller H, Cohrs CM, Almaça J, Enos SJ, Beery M, et al. Pancreas Tissue Slices From Organ Donors Enable In Situ Analysis of Type 1 Diabetes Pathogenesis. JCI Insight (2020) 5(8):e134525. doi: 10.1172/ jci.insight. 134525

81. Luce S, Guinoiseau S, Gadault A, Letourneur F, Blondeau B, Nitschke P, et al. Humanized Mouse Model to Study Type 1 Diabetes. Diabetes (2018) 67 (9):1816-29. doi: 10.2337/db18-0202

82. Lv Z, Bian Z, Shi L, Niu S, Ha B, Tremblay A, et al. Loss of Cell Surface CD47 Clustering Formation and Binding Avidity to Sirp $\alpha$ Facilitate Apoptotic Cell Clearance by Macrophages. J Immunol (2015) 195(2):661-71. doi: 10.4049/ jimmunol.1401719

83. Cui L, Chen SY, Lerbs T, Lee JW, Domizi P, Gordon S, et al. Activation of JUN in Fibroblasts Promotes Pro-Fibrotic Programme and Modulates Protective Immunity. Nat Commun (2020) 11(1):2795. doi: 10.1038/s41467-020-16466-4

84. Gurzov EN, Ortis F, Bakiri L, Wagner EF, Eizirik DL. JunB Inhibits ER Stress and Apoptosis in Pancreatic Beta Cells. PloS One (2008) 3(8):e3030. doi: 10.1371 /journal.pone. 0003030

85. Rouillard AD, Gundersen GW, Fernandez NF, Wang Z, Monteiro CD, McDermott MG, et al. The Harmonizome: A Collection of Processed Datasets Gathered to Serve and Mine Knowledge About Genes and Proteins. Database (Oxf) (2016) 2016:baw100. doi: 10.1093/database/baw100

86. Klec C, Ziomek G, Pichler M, Malli R, Graier WF. Calcium Signaling in B-Cell Physiology and Pathology: A Revisit. Int J Mol Sci (2019) 20(24):6110. doi: $10.3390 / \mathrm{ijms} 20246110$ 
87. Oldenborg PA. CD47: A Cell Surface Glycoprotein Which Regulates Multiple Functions of Hematopoietic Cells in Health and Disease. ISRN Hematol (2013) 2013:614619. doi: 10.1155/2013/614619

88. Sharp RC, Abdulrahim M, Naser ES, Naser SA. Genetic Variations of PTPN2 and PTPN22: Role in the Pathogenesis of Type 1 Diabetes and Crohn's Disease. Front Cell Infect Microbiol (2015) 5:95. doi: 10.3389/fcimb.2015.00095

89. Størling J, Pociot F. Type 1 Diabetes Candidate Genes Linked to Pancreatic Islet Cell Inflammation and Beta-Cell Apoptosis. Genes (Basel) (2017) 8(2):72. doi: $10.3390 /$ genes 8020072

90. Ling Y, Maile LA, Lieskovska J, Badley-Clarke J, Clemmons DR. Role of SHPS-1 in the Regulation of Insulin-Like Growth Factor I-Stimulated Shc and Mitogen-Activated Protein Kinase Activation in Vascular Smooth Muscle Cells. Mol Biol Cell (2005) 16(7):3353-64. doi: 10.1091/mbc.e04-10-0918

91. Shapiro MR, Wasserfall CH, McGrail SM, Posgai AL, Bacher R, Muir A, et al. Insulin-Like Growth Factor Dysregulation Both Preceding and Following Type 1 Diabetes Diagnosis. Diabetes (2020) 69(3):413-23. doi: 10.2337/db190942

92. Xu K, Jin L, Xiong M. Functional Regression Method for Whole Genome eQTL Epistasis Analysis With Sequencing Data. BMC Genomics (2017) 18 (1):385. doi: 10.1186/s12864-017-3777-4

93. Törn C, Hadley D, Lee HS, Hagopian W, Lernmark Å, Simell O, et al. Role of Type 1 Diabetes-Associated SNPs on Risk of Autoantibody Positivity in the TEDDY Study. Diabetes (2015) 64(5):1818-29. doi: 10.2337/ db14-1497

94. Shapiro MR, Thirawatananond P, Peters L, Sharp RC, Ogundare S, Posgai AL, et al. De-Coding Genetic Risk Variants in Type 1 Diabetes. Immunol Cell Biol (2021) 99:496-508. doi: 10.1111/imcb.12438

Conflict of Interest: The authors declare that the research was conducted in the absence of any commercial or financial relationships that could be construed as a potential conflict of interest.

Publisher's Note: All claims expressed in this article are solely those of the authors and do not necessarily represent those of their affiliated organizations, or those of the publisher, the editors and the reviewers. Any product that may be evaluated in this article, or claim that may be made by its manufacturer, is not guaranteed or endorsed by the publisher.

Copyright (c) 2021 Sharp, Brown, Shapiro, Posgai and Brusko. This is an open-access article distributed under the terms of the Creative Commons Attribution License (CC BY). The use, distribution or reproduction in other forums is permitted, provided the original author(s) and the copyright owner(s) are credited and that the original publication in this journal is cited, in accordance with accepted academic practice. No use, distribution or reproduction is permitted which does not comply with these terms. 